\title{
O Totalmente Outro: Alguns aspectos da Crítica de Carl Schmitt ao Liberalismo
}

\author{
The wholy other one: some aspects of schmitt's \\ critique to liberalism
}

\author{
Bernardo Ferreira ${ }^{1}$
}

\section{Resumo}

O presente artigo desenvolve, de modo original, a crítica elaborada por Carl Schmitt ao liberalismo, demonstrando como a perspectiva adotada pelo liberalismo conduz inevitavelmente ao oposto que ela se propõe. Espera-se, ao final, demonstrar como a reflexão de Carl Schmitt é um válido instrumento para a compreensão das estruturas jurídicas e políticas de nossa época.

Palavras-chave: Schmitt, Liberalismo, Política, Filosofia do Direito

\begin{abstract}
This paper develops an original critique by Carl Schmitt against to liberalism, demonstrating how the perspective adopted by liberalism inevitably leads to the opposite of what it intends. It is hoped, ultimately, to demonstrate how the reflection of Carl Schmitt is a valid instrument for understanding the legal and political structures of our time.
\end{abstract}

Key-words: Carl Schmitt, Liberalism, Politics, Philosophy of Right

A tradição liberal é, sem dúvida, o principal adversário contra o qual se dirige a teoria política de Schmitt nos anos 1920 e

\footnotetext{
Professor da área de Ciência Política do Departamento de Ciências sociais da Universidade do Estado do Rio de Janeiro (UERJ). Autor do livro O risco do político. Critica ao liberalismo e teoria política no pensamento de Carl Schmitt (Belo Horizonte: UFMG, Rio de Janeiro: IUPERJ, 2004). Abreviações: BP - Der Begriff des Politischen; D - Die Diktatur; DArD - Über die drei Arten des rechtswissenschaftlichen Denkens; GLhP - Die geistesgeschichtliche Lage des heutigen Parlamentarismus; HV - Der Hüter der Verfassung; LL - Legalität und Legitimität; LSTH - Der Leviathan in der Staatslehre des Thomas Hobbes; PT - Politische Theologie; PuB - Positionen und Begriffe; RK - Römischer Katholizismus und politische Form; VL - Verfassungslehre. O texto que se segue retoma e reelabora discussões anteriormente desenvolvidas no meu livro O risco do político. Critica ao liberalismo e teoria política no pensamento de Carl Schmitt. Belo Horizonte: UFMG, Rio de Janeiro: IUPERJ, 2004.
}

Ano $13 \cdot$ n. $1 \cdot$ jan./jun. $2013-139$ 
início da década de 1930. A polêmica contra o liberalismo ocupa um lugar decisivo na sua produção intelectual e a imagem que ele faz a seu respeito é de fundamental importância para compreender o seu próprio pensamento. Isso porque a tradição liberal desempenha na sua reflexão teórica um duplo papel: ela é pensada e constituída como objeto de crítica e como uma espécie de contraimagem, em relação à qual Schmitt elabora as suas próprias idéias. Assim, ao traçar um retrato do ideário liberal, ele está, em grande parte, definindo a sua própria posição ${ }^{2}$.

$\mathrm{Na}$ sua análise do liberalismo, Schmitt privilegia o que ele mesmo denomina de "fundamento espiritual último" (GLhP, 41) do ideário e das instituições liberais. Seu interesse está menos voltado para a análise de uma experiência histórica específica, do que para uma "estrutura de pensamento"3. Como tal, o liberalismo teria sobrevivido ao seu contexto histórico, mantendo-se, no entanto, como a forma dominante de conceber a vida política ${ }^{4}$. Portanto, a discussão de Schmitt sobre o liberalismo pode ser vista como uma tentativa de pôr em evidência as premissas fundamentais dessa "estrutura de pensamento", extraindo delas as suas

2 Nesse sentido, creio ser possível concordar, pelo menos em parte, com a afirmação de Leo Strauss de que o pensamento de Schmitt seria um "liberalismo com sinal trocado" (Strauss, Leo. "Anmerkungen zu Carl Schmitt, Der Begriff des Politischen" (1932). In: Hobbes’ politische Wissenschaft. Neuwied: Luchterhand, 1965, p. 180). Karl Löwith, em termos um pouco mais genéricos, sustenta um ponto de vista semelhante, quando observa que "as exposições de Schmitt são essencialmente 'polêmicas', ou seja, não se dirigem apenas casualmente a isso ou àquilo para clarificar criticamente a sua opinião, mas a sua própria 'exatidão' baseia-se totalmente naquilo contra que se dirigem" (Löwith, Karl. "Der okkasionelle Dezisionismus von Carl Schmitt" (1935) In: Gesammelte Abhandlungen. Stuttgart: Kohlhammer, 1960, p. 93)

3 Kervégan, Jean-François - Hegel, Carl Schmitt. Le politique entre spéculation et positivité, Paris, Puf, 1993, p. 111.

4 Dentre as muitas ocasiões onde este ponto de vista se torna manifesto, gostaria de destacar o seguinte trecho, no qual Schmitt discute a permanência das premissas do constitucionalismo liberal na Alemanha dos anos 1930: "a situação constitucional do presente se caracteriza, em primeiro lugar, pelo fato de que numerosas instituições e normas do século XIX permaneceram inalteradas, mas a situação atual, comparada com a anterior, se modificou totalmente" (HV, 73). 
consequências lógicas e políticas.

Não é casual, portanto, que a representação que Schmitt nos propõe do liberalismo esteja dominada pela imagem de "uma sistemática e consequência impressionantes" (BP, 78$)$ que caracterizariam essa tradição intelectual. Para ele, o liberalismo se apresenta como "um sistema metafísico, compreensivo, conseqüente" $(G L h P, 45)$, cuja lógica interna precisaria ser exposta, evidenciando o caráter eminentemente político "sistema pretensamente apolítico e aparentemente até antipolítico" (BP, 78). Segundo Carl Schmitt, essa característica do pensamento liberal resulta de uma tentativa de neutralizar e despolitizar a existência política. O liberalismo, nos diz ele, dilui os antagonismos políticos em contraposições despojadas de toda carga polêmica. Essa perspectiva neutralizante desembocaria em uma prática e em um pensamento que se definiriam de forma negativa e crítica em relação a todas as manifestações da vida política. Como resultado, o liberalismo seria incapaz de elaborar uma concepção verdadeiramente política a respeito do Estado ou de qualquer outro aspecto da existência política. Assim, observa Schmitt,

"o pensamento liberal, de uma maneira sumamente sistemática, contorna ou ignora o Estado e a política e move-se, em lugar disso, em uma típica polaridade, em permanente retorno, entre duas esferas heterogêneas, ou seja, entre ética e economia, espírito e negócio, cultura [Bildung] e propriedade. A desconfiança crítica contra o Estado e a política se esclarece facilmente a partir dos princípios de um sistema para o qual o indivíduo deve permanecer terminus a quo e terminus ad quem" (BP, 69-70) $)^{5}$.

Para Schmitt, a análise dos desdobramentos desses princípios individualistas deve, ao mesmo tempo, pôr em evidência o seu caráter polêmico e a natureza da sua oposição a tudo que traz a marca do político. Com isso, sua crítica do liberalismo se

As expressões "terminus a quo" e "terminus ad quem" significam, respectivamente, "termo do qual" e "termo para o qual".

Ano $13 \cdot$ n. $1 \cdot$ jan./jun. $2013-141$ 
desdobra em diferentes direções: ela se dirige tanto ao que seriam os pressupostos do sistema liberal, quanto aos resultados que se poderiam deduzir deles. Por um lado, ela se volta contra o seu "fundamento espiritual último", contra os seus princípios individualistas e busca assinalar a sua recusa do político; por outro, procura dar conta das consequências lógicas e políticas que se poderiam extrair desses princípios, apontando para os seus desdobramentos e para as suas diversas manifestações na vida política concreta. Daí, as diferentes formas assumidas por essa crítica e os diferentes temas com que ela se enfrenta: romantismo político, parlamentarismo, Estado de direito, normativismo, pluralismo, concepção puramente legal da legitimidade, pacifismo. Esse quadro de problemas poderia ser ampliado, assim como para cada um deles haveria possibilidade encontrar um antípoda no pensamento de Schmitt.

Para discutir a imagem que este autor faz da tradição liberal, gostaria de me deter sobre um desses problemas: a sua análise sobre o conceito de lei característico da constituição do Estado de direito. Não pretendo, com isso, apresentar um panorama geral da interpretação de Schmitt sobre o liberalismo, mas sim encontrar uma via de acesso a seu pensamento político. Interessa-me, em particular, a sua crítica ao normativismo do pensamento liberal.

Segundo Schmitt, "a constituição do Estado de direito burguês corresponde nos seus princípios ao ideal de constituição do individualismo burguês" $(V L, 125)$. Por esse motivo, trata-se de uma constituição que teria por objetivo preservar a liberdade do indivíduo em face do Estado. De acordo com essa perspectiva, o poder do Estado teria que ser cerceado e sua ação controlada sob a forma de um sistema de competências delimitadas. Sendo assim, a "organização do Estado é realizada de acordo com uma perspectiva crítica e negativa em relação ao poder do Estado proteção do cidadão contra o abuso do poder do Estado" (VL, 41). O foco da ordem constitucional é a limitação do exercício do poder estatal, de modo que não é tanto o Estado que vem a ser organizado, mas sim os meios e os métodos do seu controle (cf. VL, 41). 
Assim, da "ideia fundamental" (VL, 126) da liberdade do indivíduo decorreriam os dois princípios do constitucionalismo liberal:

\begin{abstract}
"em primeiro lugar, um princípio de repartição: a esfera de liberdade do indivíduo é pressuposta como um dado anterior ao Estado, e a liberdade do indivíduo é em princípio ilimitada, enquanto a competência do Estado de intervir nessa esfera é em princípio limitada. Em segundo lugar, um principio de organização (...) o poder estatal (em princípio limitado) é dividido e compreendido em um sistema de competências circunscritas" (VL, 126, grifos do autor).
\end{abstract}

Para Schmitt, a maior parte das constituições do seu tempo trariam a marca dos princípios do Estado de direito. O princípio da repartição encontraria a sua expressão na ideia de que uma constituição deve garantir os direitos fundamentais ou de liberdade (Grundrechte/Freiheitsrechte) dos seus cidadãos. Já o princípio de organização se apresentaria sob a forma da teoria da divisão de poderes (Gewaltenteilung), que preconiza não só a divisão do poder do Estado em um conjunto de esferas de ação delimitadas, mas também a criação de um sistema de contrapesos, de um balanceamento entre elas (cf. VL, 126-127).

A condição de que esse ideal de controle do poder público se realize está, para Schmitt, na possibilidade de submeter o conjunto da vida do Estado a um sistema de normas jurídicas, de tal maneira que todo conflito possa ser resolvido segundo uma forma judicial. No Estado de direito, a garantia do indivíduo contra as ingerências na sua esfera de liberdade estaria na idéia de que o controle jurídico do exercício do poder seria assegurado pela independência dos juízes em relação a toda outra instância que não a própria lei. Nesse sentido, o Estado de direito é um "Estado de lei [Gesetzesstaat]", pois ele estaria baseado na "dominação da lei" (VL, 138). Mas o que significa falar de uma "dominação da lei" na perspectiva do liberalismo? Para o liberalismo, nos diz Schmitt, a lei só se torna uma garantia da liberdade do indivíduo a partir do momento em que ele estiver ao abrigo dos caprichos 
do legislador e que a sua independência não for atingida pela imprevisibilidade das determinações legais. A "dominação da lei" colocaria no indivíduo o limite e a própria razão de ser da ordem legal. Portanto, onde a lei impera, "o legislador está vinculado à sua própria lei e a sua competência legislativa não é o meio de uma dominação arbitrária" (VL, 139). O conceito de lei do Estado de direito se definiria, antes de tudo, através de uma "contraposição", pois, "tanto do ponto de vista histórico quanto conceitual", ele significaria "uma recusa da 'dominação dos homens"” (VL, 139). Entretanto, segundo Schmitt, para que este tipo de oposição possa fazer sentido, é preciso,

\footnotetext{
"introduzir no conceito de lei certas qualidades que tornem possível a diferença entre uma norma jurídica e uma mera ordem conforme a vontade [willensmäßigen Befehl] ou uma medida [Maßnahme]" (VL, 138, grifos do autor).
}

Para atender a esses requisitos, a lei deveria assumir um caráter abstrato, impessoal; deveria ser válida igualmente para todos e, portanto, indiferente à especificidade das situações concretas; deveria, enfim, se apresentar como uma norma geral. A generalidade da lei seria a condição para que o próprio legislador estivesse submetido a ela. Somente assim, ele agiria segundo regras universalmente válidas, sem que medidas derivadas de circunstâncias particulares pudessem reivindicar a condição de lei. Somente assim, seria possível imaginar uma situação na qual "não se domina mais ou se comanda, porque apenas se fazem valer de forma impessoal normas vigentes" ( $L L, 8)$. Ao se apresentar como uma norma geral, o conceito de lei do liberalismo, acabaria por revelar os seus fundamentos tanto históricos quanto filosóficos. Por um lado, ele teria surgido em contraposição à idéia de lei característica das monarquias absolutas. A lei como medida (Maßnahme), como ordem pessoal emanada da vontade do príncipe se oporia à norma abstrata e impessoal do Estado de direito burguês. A onipotência do governante legibus solutus deveria ceder lugar à submissão do legislador à sua própria lei. Dessa maneira, a condição para que a norma jurídica se revestisse de um cunho de ge- 
neralidade estaria na dissociação do par lei/vontade característico do absolutismo. Pela sua própria natureza, noção liberal de lei, se oporia a conceitos que teriam desempenhado um papel central na estruturação histórica da esfera público-estatal moderna.

A ideia liberal de uma "dominação da lei" negaria a necessidade de uma instância que atribuísse validade à própria lei. Esta já não encontraria o seu fundamento na auctoritas do Estado, mas em uma veritas antecedente à própria ordem política ${ }^{6}$. Segundo Schmitt, a anterioridade e independência dos princípios jurídicos em relação à esfera estatal tornariam, em última análise, a autoridade do Estado senão dispensável, pelo menos secundária; ao mesmo tempo, favoreceriam a associação entre o seu exercício e a possibilidade do abuso de poder. Com isso, a "dominação da lei" poderia ser vista como "um triunfo do direito sobre o poder" (GLhP, 61). Nada mais característico desse fato do que a convicção, própria ao constitucionalismo liberal, de que haveria condições de "abranger, sem resíduos, todas as possibilidades de ação do Estado em um sistema de normas" (VL, 150). Ao atribuir a esse sistema de normas a capacidade de predeterminar o futuro ${ }^{7}$, o liberalismo tenderia a desconhecer e a recusar a própria ideia de soberania. $\mathrm{Na}$ análise de Schmitt, a defesa liberal da "dominação da lei" toma como certa a possibilidade de substituir a soberania do Estado pela soberania da lei, contrapondo a validade impessoal de uma norma abstrata ao caráter pessoal da decisão concreta do soberano. A crença na possibilidade de subsunção da totalidade da existência estatal em um sistema de normas teria como consequência final a transformação da própria constituição na "lei fundamental desse sistema de leis" $(V L, 131)$. Isso implicaria, observa Schmitt,

\footnotetext{
6 A oposição entre auctoritas e veritas remete à frase de Hobbes, insistentemente retomada por Schmitt: auctoritas non veritas facit legem. Segundo Schmitt, ao se opor ao absolutismo monárquico, o liberalismo teria invertido o significado da proposição: "a lei é veritas, em oposição à pura auctoritas” (GLhP, 56).

Cf. Freund, Julien - "Schmitt's political thought" in Telos, $\mathrm{n}^{\circ}$ 102, 1995, p. 11.
}

Ano $13 \cdot$ n. $1 \cdot$ jan./jun. $2013-145$ 
“a ficção [es wird fingiert] de que, primeiro, a constituição nada mais é do que um sistema de normas legais, segundo, de que esse sistema é fechado, e, terceiro, de que ele é 'soberano', ou seja, não pode em ponto algum ser rompido ou sequer influenciado com base nas razões e necessidades da existência política" $(V L, 131)$.

A dissociação entre lei e vontade promovida pelo liberalismo não estaria apenas condicionada pela oposição ao conceito de lei do absolutismo monárquico. Ela também seria tributária da "diferenciação racionalista entre o geral (...) e o singular" (GLhP, 53). A contraposição de natureza histórica e política se apresentaria, ao mesmo tempo, como um dualismo de caráter filosófico e lógico, a partir do qual uma série de antíteses poderiam ser derivadas. Assim como o geral se opõe ao singular, o alcance universal da lei se oporia à finalidade particular da ordem, a permanência da norma jurídica à natureza provisória e circunstancial da medida, as formulações abstratas do direito às injunções concretas de uma medida, a racionalidade dos princípios legais à imprevisibilidade do arbítrio humano. Em última análise, o conteúdo racionalista do conceito de lei da tradição liberal teria como pressuposto a crença numa correspondência entre a norma jurídica e as noções de justiça e verdade. Para Schmitt, a dissociação entre lei e vontade deriva da imagem de que a lei é em primeiro lugar "algo de geral-racional; não é voluntas, mas sim ratio" (VL, 139, grifo do autor).

$\mathrm{Na}$ base distinção liberal entre voluntas e ratio, estaria implícito, segundo Schmitt, um contraste entre ser e dever-ser que poderia ser remontado às doutrinas do direito natural dos séculos XVII e XVIII. Nesse quadro, a validade da lei estaria associada ao fato de que ela seria a expressão de princípios justos e racionais, "que têm validade anterior e acima de qualquer ser político" (VL, 9). O ponto de partida da concepção liberal de lei estaria, portanto, na crença jusnaturalista de que a normas jurídicas "contêm um autêntico dever-ser, sem levar em conta a realidade do seu ser [seinsmäßige Wirklichkeit], ou seja, a realidade jurídico-positiva" $(V L, 9)$. No entanto, a insistência na anterioridade e independência da norma em relação à realidade política teria se mantido no pen- 
samento liberal, a despeito do "direito natural ter perdido a sua evidência" (VL, 142). Uma vez que "todas as outras características da lei, como ordenação substancial-racional, justa e razoável, se tornaram (...) relativas e problemáticas" (VL, 156), uma propriedade teria permanecido essencial para sustentação do conceito de lei característico do liberalismo: o caráter geral da norma jurídica. Uma racionalidade puramente formal tomaria o lugar da concepção metafísica da Razão e da Justiça, da crença nos princípios de uma racionalidade substancial, e a ideia da lei como norma geral se apresentaria como o "último resíduo do fundamento ideal", como a "última garantia" $(V L, 142)$ das oposições entre lei e medida, ratio e voluntas próprias à tradição liberal. Nesse quadro, as disposições particulares se apresentariam como uma aplicação especial de normas gerais, de tal maneira que o conjunto da vida política poderia ser submetido à racionalidade da lei. Para Schmitt, resultado final desse tipo de perspectiva estaria na "ilusão" de que

\footnotetext{
"seria possível instituir uma via legal e um procedimento legal para todos os esforços, objetivos e movimento imagináveis, inclusive para os mais radicais e revolucionários, um procedimento que lhes permitisse alcançar sem violência e sem subversão o seu objetivo, que funcionasse, ao mesmo tempo, instituindo ordem e, no entanto, fosse totalmente 'neutro em relação a valores' $(L L, 14)$.
}

Assim, a afirmação da anterioridade e da independência do dever-ser da norma em relação ao ser da realidade traria consigo a crença na possibilidade de que "na realidade concreta do ser político" governassem "ordens abstratas e séries de normas" (BP, 72). Onde a norma prevalecesse não haveria lugar para a violência, para a sublevação ou para as relações de força e de poder. A prioridade da norma e a tendência à despolitização inerentes ao pensamento liberal estariam a serviço da limitação da esfera de atuação do Estado e da consequente ampliação do âmbito da liberdade social. A redução da legalidade à sua dimensão procedimental seria uma das expressões mais claras da crença na possibilidade de uma ordem de caráter imanente. A ordem jurídico-política se veria transformada no mero funcionamento de um 
complexo de normas legais, que só reconhecem como critério a eficiência impessoal. Nesse quadro, o sistema de legalidade poderia ser concebido, como observa Schmitt em um texto de 1934, à semelhança das regras que regem o trânsito nas modernas sociedades industriais. Nesse último, o arbítrio humano é, em grande medida, eliminado, para que a circulação possa obedecer a um plano preestabelecido. Em suas palavras,

\footnotetext{
"o trânsito bem regulado em uma rua de grande movimento numa metrópole moderna oferece o melhor retrato de semelhante 'ordem'. Aqui o último vestígio de dominação e arbítrio humanos que o guarda de trânsito ainda poderia exibir é substituído por sinais automáticos coloridos que funcionam de forma precisa" (DArD, 16).
}

O papel da ordem legal seria, portanto, o de tornar previsível a atividade estatal, abrangendo-a numa teia de normas, capazes de reger o conjunto da vida política de acordo com a lógica de uma funcionalidade operacional. Para Schmitt, a crença na possibilidade de eliminação do arbítrio humano característica desse tipo de perspectiva seria representativa da tendência a pensar a ordem jurídico-política à imagem e semelhança do mundo natural. Nesse quadro, ela pode ser concebida em sua total imanência como algo que independe da vontade humana, que prescinde de qualquer instância que a institua e que, em última análise, tem o seu fundamento de validade em si mesma. Essa coisificação do sistema de legalidade teria como consequência última a imagem de que, em lugar do governo de homens sobre outros homens, existiria um governo de normas que se aplicariam, se interpretariam e se sancionariam a si mesmas.

A neutralização da vida política promovida pelo liberalismo seria, portanto, solidária da imagem de uma "sociedade' que tem a sua ordem em si mesma" $(B P, 60)$. Uma ordem que, em última análise, dispensaria o governo do homem sobre o homem, porque se manteria capaz de se manter dentro dos limites da normalidade e de uma convivência inteiramente regulada. Dessa forma, o normativismo da "estrutura de pensamento" liberal estaria 
a serviço da convicção de que a política e o Estado poderiam ser, senão eliminados, pelo menos reduzidos a um mínimo necessário. O significado desse normativismo se tornaria mais evidente quando associado a duas ideias centrais, a dois princípios gerais da metafísica liberal: a "livre concorrência e a harmonia preestabelecida" (GLhP, 45). Mais do que categorias do liberalismo econômico, essas duas noções estariam na base da própria imagem da sociedade construída pelo "sistema liberal". A análise de Schmitt sobre o parlamentarismo liberal é característica desse ponto.

Para ele, o "núcleo último" (GLhP, 30) do parlamentarismo estaria na crença liberal numa ordenação impessoal da vida coletiva e na "dominação da lei" como uma via de supressão do governo do homem pelo homem. O parlamento seria o lugar onde, em tese, o poder pessoal dos homens se converteria na dominação impessoal da lei. Para Schmitt, o que assegura essa crença no corpo legislativo como lugar de transformação da voluntas em ratio, seria a imagem de que as deliberações parlamentares são obtidas através da discussão pública. Ali, as resoluções se fazem

\footnotetext{
"parlamentando, pesando argumento e contra-argumento e (...), por conseguinte, têm logicamente um caráter distinto de uma ordem [Befehl] baseada na autoridade" (GLhP, 54)
}

Por essa razão, uma premissa fundamental do sistema parlamentar residiria na imagem de um confronto público de opiniões cujo resultado final seria a verdade. Discussão e publicidade (Öffentlichkeit) seriam, segundo ele, os dois princípios centrais do parlamentarismo. Para Schmitt, a crença na discussão pública como um instrumento de obtenção da verdade e da justiça seria típica do liberalismo. Da mesma forma que a competição dos agentes econômicos no mercado seria capaz de produzir uma ordem harmônica, a verdade seria o produto da concorrência entre opiniões divergentes. Assim, na análise de Schmitt, a ordem parlamentar é, antes de tudo, uma ordem de natureza social que pretende dar um caráter público ao intercâmbio que os indivíduos mantêm a partir da sua existência privada. Na liberdade da opinião privada estaria a possibilidade de constituição de uma opinião pública 
capaz de se contrapor ao poder e de controlá-lo. Dessa forma, a noção de publicidade característica do parlamentarismo estaria associada a uma reivindicação de transparência do exercício do poder e à defesa de uma ordem oriunda da sociedade e contraposta à ordem estatal.

Assim, o sistema parlamentar estaria associado a uma representação dualista da realidade política, baseada na diferenciação entre Estado e sociedade. Como observa Schmitt,

\footnotetext{
“a representação popular, o parlamento, o corpo legislativo foi pensado como o palco no qual a sociedade se apresentava e fazia frente ao Estado. Aqui ela deveria se integrar no Estado (ou o Estado nela)" (HV, 74).
}

Nesse contexto, a discussão pública seria o instrumento por excelência de integração da sociedade no Estado. No parlamento, o processo de integração da sociedade no Estado se realizaria sob a forma da criação de uma ordem legal de alcance universal. Na análise de Schmitt, a vontade geral surgida nas decisões parlamentares é a maneira pela qual o dominação da lei se realiza como uma expressão da auto-organização da sociedade. Portanto, o apelo do parlamentarismo seria indissociável da imagem do parlamento como um lugar de transformação da lei numa expressão da capacidade de autodeterminação racional da sociedade. Manifestação da vontade geral do povo, a lei deixaria de ser um instrumento de uma dominação heterônoma, para se converter na forma por excelência de emancipação da sociedade em relação ao poder do Estado. Através da discussão racional, os princípios da vida pública surgiriam espontaneamente da própria dinâmica da vida social, do intercâmbio espiritual entre os indivíduos. No parlamento, o exercício do poder perderia a sua dimensão de arbítrio, deixando de ser a expressão de uma vontade particular para se adequar à universalidade de normas racionais. A ordem surgida da discussão em comum traduziria, em última análise, a coincidência da sociedade consigo mesma, de tal forma que o fundamento atividade política deveria ser buscado no dinamismo do processo de interação social. A “dominação da lei” 
longe de ser algo que se imporia de fora, sobre a vida social, se apresentaria como um fato surgido dela mesma. Daí a crença na possibilidade de uma emancipação em face do Estado e das relações de poder, realidades exteriores e estranhas à dinâmica auto-regulada da sociedade.

Dessa forma, a ordem liberal seria, antes de tudo, uma ordem não instituída, ou melhor, que se institui a si mesma. Concebida como um agregado de indivíduos autônomos, a sociedade no liberalismo é o lugar por excelência da produção dessa ordem. Essa última surge do própria dinâmica da vida social como o produto espontâneo das interações que os indivíduos estabelecem uns com os outros. No liberalismo, a vida social se apresentaria como o lugar em que o exercício da liberdade individual se converteria em convivência autorregulada, de tal forma que o conflito, as relações de força e dominação entre os homens se transformariam em realidades secundárias e, quem sabe, dispensáveis. Nesse quadro, em que, em tese, a sociedade encontra a sua ordem em si mesma, as relações entre os homens se veriam reduzidas a uma dimensão horizontal. Assim, a ordem liberal teria como pressuposto uma oposição entre a autonomia das relações sociais e a heteronomia da dominação política. Em função disso, o pensamento liberal demonstraria incapacidade de compreensão, e até mesmo franca hostilidade, diante de expressões que, segundo Schmitt, seriam típicas da existência política e estatal, tais como o poder, a força, a autoridade, a guerra, a soberania. Dessa forma, observa ele, para o "liberalismo político, o Estado e a política são concebidos como o "totalmente outro"” $(P T, 7)$.

Nesse sentido, o normativismo do pensamento liberal seria a expressão do ideal de uma sociedade governada pelo princípio da imanência. O "dominação da lei" longe de ser algo que se imporia de fora, sobre a vida social, se apresentaria como um fato surgido dela mesma. Daí a crença na possibilidade de uma emancipação em relação ao Estado e a política, que se apresentariam como realidades exteriores à dinâmica autorregulada da sociedade. Aos olhos de Schmitt, o liberalismo aparece, portanto, como uma ontologia da vida social cujos pressupostos seriam 
imanentes à própria vida social; ou seja, ele aparece como um "sistema de pensamento" que pretende ser, se é possível usar esses termos, uma ontologia social do social.

Para Schmitt, o normativismo do pensamento liberal se torna insustentável a partir do momento em que uma das suas premissas fundamentais pode ser colocada em questão: a natureza evidente e incontroversa da norma. Como ele observa em Legalidade e legitimidade,

\begin{abstract}
"nenhuma norma (...) se interpreta ou se aplica, se protege ou se defende a si mesma; nenhuma validade normativa se faz valer a si mesma; e também não existe - caso não queiramos nos estender em metáforas e alegorias - nenhuma hierarquia de normas, apenas hierarquias de homens e de instâncias concretas" (LL,53).
\end{abstract}

Esse trecho é sob diversos aspectos exemplar, seja pelas repetidas vezes em que afirmações semelhantes aparecem em sua obra $^{8}$, seja porque, em alguma medida, sintetiza, numa fórmula, sua crítica ao problema do fundamento de uma ordem normativa. Para Schmitt, como se pode ver, o fundamento de validade de um sistema normativo não é jamais algo evidente em si mesmo. Em última análise, nenhuma norma contém em si o princípio da sua própria validade. Mais ainda: não haveria como derivar a validade de uma ordem normativa de uma suposta universalidade ou racionalidade dos seus conteúdos. Para que isso fosse possível, seria necessário pressupor a existência no interior da vida social de um quadro de valores incontroverso, de algum tipo de consenso normativo. $\mathrm{Na}$ ausência de semelhante consenso, se colocaria a necessidade de instituir condições fáticas em que as normas pudessem ter vigência, ou seja, em que a sua validade viesse a ser "universalmente" reconhecida. Nesse caso, porém, a universalidade desse reconhecimento já não seria uma decorrência da

8 Para observações do mesmo gênero, veja-se, por exemplo: $D A r D, 14 ; B P, 72 ; V L$, 9, 56, 90 .

152 - Universidade Católica de Pernambuco 
natureza em si mesma universal e incontroversa dos princípios normativos, mas o resultado da criação de um "meio homogêneo" $(D, 133$ e $P T, 19)$. A impossibilidade de um consenso fundado em critérios universais e objetivos traria consigo a exigência de uma instância de validação da norma. Noções como "bem comum", "justiça", "paz", "ordem pública", "liberdade" à medida que carecem de um sentido unívoco e socialmente partilhado, não se tornam efetivas sem que uma interpretação específica se imponha. Elas precisam se revestir de um significado concreto para ter algum tipo de validade ${ }^{9}$. Se um imperativo moral ou jurídico precisa ser interpretado para ganhar efetividade, se a sua validade não está automaticamente dada por seu conteúdo, se é necessário criar as condições da sua vigência, a questão se transfere do plano de um juízo ético ou jurídico - incondicionado e puramente normativo para o plano do conflito político.

Para Carl Schmitt, a impossibilidade de um conteúdo normativo se tornar efetivo por si mesmo se revelaria em toda a sua amplitude à luz do problema da exceção. Na situação anormal, seria possível reconhecer as condições de validade de uma norma. Segundo ele, essa validade não é, como uma perspectiva racionalista gostaria de crer, incondicional: a norma não pode valer numa situação de exceção, ou seja, numa situação fora da norma, na qual, por princípio, ela não se aplica. Dessa forma, observa Schmitt,

"quem parte da idéia de estar em presença de uma situa-
ção anormal - ou porque olha o mundo numa anormalida-
de radical, ou porque considera uma dada situação como
anormal - resolverá o problema da política, da moral e
do direito de forma distinta de quem está convencido da
sua normalidade de princípio, somente transtornada por

Cf. "Zu Friedrich Meineckes Idee der Staatsräson" (1926) in PuB, 57; LL, 33, VL, 37. Como observa George Schwab, em Schmitt, "toda afirmação religiosa, filosófica ou moral precisa de interpretação" (The Challenge of exception, Nova York, Greenwood, 1989, $2^{\mathrm{a}}$ ed., p. 46). 
pequenas perturbações"10.

O ponto de vista da "normalidade de princípio" seria incapaz de resolver a questão do fundamento de validade de uma norma, pois tomaria a própria situação normal como algo antecipadamente garantido, ou seja, conceberia as condições em que uma norma é válida como uma realidade previamente dada. No entanto, pensa Schmitt, "toda norma geral exige uma configuração normal das relações de vida" $(P T, 19)$. Em face da perspectiva do estado de exceção, diante da possibilidade de uma situação concreta em que a validade de um sistema normativo é necessariamente suspensa, seria preciso admitir que a "normalidade fática [faktische]" não é apenas um "pressuposto externo", mas sim algo que diz respeito à "validade imanente" $(P T, 19)^{11}$ de uma norma. Nessa perspectiva, afirma Schmitt categoricamente, "todo direito é 'direito situacional' [, Situationsrecht“]” (PT, 19). A vigência de um sistema normativo precisaria ser concebida em termos das condições concretas em que uma proposição é publicamente reconhecida como norma. Daí a importância de se considerar a realidade a partir do "caso-limite" de uma situação anormal - cuja suspensão

10 "Zu Friedrich Meineckes Idee der Staatsräson" (1926) in PuB, 53.

11 Em DArD, de 1934, Schmitt reafirma esse ponto: "a normalidade da situação concreta, regulada pela norma, e do tipo concreto por ela pressuposto não é, portanto, apenas um pressuposto externo, a ser desconsiderado do ponto de vista da ciência jurídica, mas uma característica jurídica essencial, interna, da validade da norma e uma determinação normativa da própria norma. Um norma pura, desligada de toda situação e tipo [situationlose und typenlose], seria um absurdo jurídico" (DArD, 20). Um dos alvos dessa insistência na importância normativa do caráter concreto da "normalidade fática" é a "teoria pura do direito" do jurista austríaco Hans Kelsen. O normativismo de Kelsen é uma das principais referências polêmicas de Schmitt na sua discussão sobre o fundamento de validade de um sistema normativo. Sobre Schmitt e Kelsen, pode-se consultar entre outros: Hofmann, Hasso - Legittimità contro Legalità. Nápoles: ESI, 1999; Portinaro, Pier Paolo. La Crisi dello Jus Publicum Europaeum. Milão: Comunità, 1982; Kervégan, Jean-François. "La critique schmittienne du normativisme kelsénien" in Herrera, Carlos-Miguel (org.). Le Droit, le Politique. Autour de Max Weber, Hans Kelsen, Carl Schmitt. Paris : L'Harmattan, 1995; Beaud, Olivier. "Carl Schmitt ou le juriste engagé” In : Schmitt, Carl. Théorie de la Constitution. Paris: PUF, 1993. 
das normas e da normalidade colocaria o problema da sua própria instauração -, e não a partir do "caso normal" $(P T, 13)$ - em que a vigência das normas se faria enganosa. A aparente naturalidade daquilo que é tido como normal seria apenas fruto de "generalizações de algo que se repete de forma ordinária" (PT, 21). Uma vez que a norma não se apresenta como evidente em si mesma e capaz de se autoinstituir, dada a impossibilidade de pressupor um consenso em torno de princípios normativos, o problema passa a estar nas condições de instauração da normalidade.

Assim, o problema da normalidade e o conceito de "normal", em Schmitt, não se colocam em termos normativos, mas acima de tudo políticos. A estabilidade e a normalidade de uma dada situação não se definem in abstracto, ela depende, para utilizar os termos do próprio Schmitt, da definição de uma "hierarquia de homens e instâncias concretas". A constituição de uma ordem normal implicaria a exclusão das ordens alternativas, já que, afirma o jurista, "não existe uma pluralidade de situações normais"12. Portanto, a questão da validade de uma ordem normativa não pode ser resolvida em função dos conteúdos das normas, mas, nas palavras do próprio Schmitt, "é preciso criar um ordenamento [Ordnung] para que o ordenamento jurídico [Rechtsordnung] tenha um sentido" $(P T, 19)$. Dessa maneira, norma jurídica e ordem política vêm a ser conceptualmente separadas, ao mesmo tempo em que se estabelece uma dependência estreita entre as regras do direito e uma "configuração normal das relações de vida". Contudo, a insistência nessa dissociação e a afirmação dessa dependência não significam uma recusa da dimensão normativa e o simples reconhecimento da prioridade das relações de força e de poder sobre o direito. Na verdade, trata-se, por um lado, de afirmar a impossibilidade de esgotar o direito na imanência do sistema de legalidade. Por outro, está em jogo a possibilidade do estabelecimento de uma ordem normativa dotada de efetividade concreta. Para Schmitt, a insistência no tema da exceção está diretamente associada

12 "Staatsethik und pluralistischer Staat" in $P u B, 160$

Ano $13 \cdot$ n. $1 \cdot$ jan./jun. $2013-155$ 
ao problema da "realização do direito" (Rechtsverwirklichung) ${ }^{13}$. O que ele rejeita, portanto, é a generalidade abstrata de uma norma contida em si mesma e desligada de toda situação concreta. Com efeito, diz-nos ele em um texto de 1934,

"a norma ou a regra não cria a ordem; ao invés disso, ela tem apenas, com base numa dada ordem e no interior dela, uma certa função reguladora, cuja validade é, numa medida relativamente restrita, autônoma e independente da situação das coisas" (DArD, 11).

Para que uma norma possa assumir um caráter geral e se elevar para além das circunstâncias particulares a serem reguladas, seria preciso introduzir algum grau de calculabilidade e regularidade na própria situação que ela pretende governar. Com isso, o problema se transfere da generalidade da norma para a relativa estabilidade da situação concreta (cf. $D, 163$ ).

A maneira como Schmitt constrói a ideia de exceção é característica do seu processo de formação de conceitos. Como observa Pasquale Pasquino, ele parte da perspectiva de que "a formação de conceitos necessita que se leve em consideração o caso-limite ou extremo, o qual, na maior parte do tempo, nada mais é do que o resultado de uma construção intelectual"14. Com isso, a ideia de exceção - de uma situação anormal porque não contida na norma - representa para Schmitt um ponto de vista

13 Para a discussão da centralidade do problema da realização do direito no pensamento jurídico de Carl Schmitt com referência aos seus textos anteriores a 1919 (com particular destaque para Der Wert des Staates und die Bedeutung des Einzelnen), vide Hofmann, Hasso. Legittimità contro Legalità; Nicoletti, Michelle - Trascendenza e Potere. La teologia política di Carl Schmitt. Brescia, Morcelliana, 1990; Duso, Giuseppe - La Rappresentanza: un Problema di Filosofia Politica, Milão, Franco Angeli, 1988.

14 Pasquino, P. "Carl Schmitt - Teoria da constituição" in Chatelet, F.; Duhamel, O.; Pisier, E. - Dicionário de obras políticas, Rio de Janeiro, Civilização Brasileira, 1993, p. 1089, grifos do autor. De acordo com Pasquino, este procedimento seria comum a outros intelectuais alemães da época de Schmitt, como Walter Benjamin e Siegfried Kracauer. Segundo esse último, "somente se pode compreender a realidade a partir dos seus extremos" (apud. ibid., p. 1094).

156 - Universidade Católica de Pernambuco 
privilegiado para se pensar o fundamento da ordem normativa. Em suas palavras, ele se revestiria de um "significado particularmente decisivo e revelador do núcleo das coisas" $(B P, 35)^{15}$. O ponto de vista extremo da situação de exceção permitiria pensar como a questão da validade de uma ordem normativa já não poderia ser concebida em termos da autossuficiência da norma, mas traria consigo a pergunta pela instância de validação da ordem. Em última análise, ela permitiria pôr a descoberto a necessidade de uma decisão como o dado inseparável, embora muitas vezes oculto, da efetividade de uma norma. A possibilidade de situações que escapam a toda delimitação normativa imporia a necessidade de uma decisão que estivesse em condições de ditar concretamente as fronteiras do direito. Aqui, insiste Schmitt, "a decisão se liberta de todo vínculo normativo e se torna absoluta num sentido próprio" $(P T, 18)$. Decidir, nessa perspectiva, seria algo mais do que a mera aplicação de uma norma. Pelo contrário, pois "de um ponto de vista normativo, a decisão nasce de um nada" (PT, 37-38). Esse fato se deveria a duas razões fundamentais.

Em primeiro lugar, numa situação de conflito, no "nada normativo" (DArD, 24) do estado de exceção, não haveria qualquer possibilidade de um consenso em torno de princípios últimos que servisse de fundamento para uma decisão. Nesse caso, diz-nos Schmitt,

"naturalmente, todos querem apenas o direito, a moral, a ética e a paz; ninguém quer cometer injustiças; mas a única questão in concreto interessante é sempre: quem vai decidir no caso concreto o que é o direito? onde está a paz? o que é uma perturbação ou ameaça da paz? com que meios elas são eliminadas? quando é que uma situa-

15 BP, p. 35. Como observa Renato Lessa, a exceção seria "sobretudo um ponto de vista para observar o que se passa no espaço público". Dessa forma, "presente ou ausente em termos reais, Schmitt faz da simulação da exceção um modo próprio de conhecimento político" (Lessa, Renato. "A política como ela é ... Carl Schmitt e o realismo político como agonia e aposta". In: Agonia, aposta e ceticismo. Belo Horizonte: Editora UFMG, 2003, p. 53).

Ano $13 \cdot$ n. $1 \cdot$ jan./jun. $2013-157$ 
ção está normal e 'pacificada'? etc."16

Uma vez que o conflito não pode ser resolvido em nome de uma norma reconhecida por todos como incondicionalmente válida, o fundamento último da decisão não obedeceria a critérios de certeza racional. Pelo contrário, ela "se torna nesse momento independente de uma fundamentação argumentativa e adquire um valor autônomo" $(P T, 37)$. A decisão implica, ao mesmo tempo, um ato de interpretação, capaz de atribuir significado concreto aos conceitos que estruturam a vida coletiva. Todavia semelhante interpretação é, antes de tudo, um ato de autoridade. Não se trata do simples reconhecimento de algo já dado, mas contém em si um "momento constitutivo" ( $P T, 37)$. A construção da ordem pública seria indissociável de um processo de produção e imputação de sentido, através do qual se eliminariam possibilidades alternativas de interpretação.

Em segundo lugar, não haveria como subsumir as diferentes situações que concretamente exigem uma decisão na generalidade abstrata de um preceito moral ou de um princípio jurídico. A existência de uma norma geral seria aqui de pouca utilidade, porque, em última análise, "a circunstância que torna necessária uma decisão permanece um momento determinante e independente" ( $P T, 36)$. Para Schmitt, a circunstância de uma autêntica decisão desafia toda delimitação normativa. Aceitar o ponto de vista da exceção significaria, portanto, reconhecer o caráter literalmente extraordinário da decisão. Ela se situaria, antes de tudo, no domínio daquilo que não pode ser previsto, daquilo que não pode ser antecipado. A exceção, observa o jurista, é "o não-subsumível" (PT, 33). Na ótica da "normalidade de princípio", a ruptura com a ordem normal se apresentaria como algo infenso à compreensão racional. Para Carl Schmitt, porém, o fato da situação fora da norma implicar uma ruptura com a ordem tornaria patente o papel de uma decisão no estabelecimento de uma "situação ordinária". Assim, a premissa da impossibilidade de uma

\footnotetext{
16 "Zu Friedrich Meineckes Idee der Staatsräson" (1926) in PuB, 57. 
correspondência imediata entre norma e realidade característica do conceito de exceção teria como outro lado da moeda a função mediadora da decisão como a condição da efetividade de uma ordem normativa.

Para o nosso autor, a decisão genuína é sempre uma decisão soberana, e a verdadeira decisão soberana é aquela que remete ao estado de exceção. Mais precisamente: "soberano é quem decide sobre o estado de exceção" $(P T, 13)$. À semelhança do conceito de exceção, Schmitt concebe a ideia de soberania como um Grenzbegriff, um conceito-limite ${ }^{17}$, construído a partir de um ponto de vista extremo. A seu ver, ela se refere a uma instância de decisão última num quadro de falência das referências normativas, ou seja, no "nada normativo" do caso de exceção. Numa situação em que todas as decisões tendem a se tornar equivalentes, o "monopólio da decisão última" $(P T, 19)$ pelo soberano significaria a possibilidade de sustar a multiplicação de interpretações sobre a natureza do interesse público e acabar com o conflito em torno dos princípios da própria ordem, instituindo autoritariamente a normalidade e os parâmetros da existência coletiva. Daí, a ideia de que "a questão da soberania é a questão da decisão de um conflito existencial" (VL, 371), ou seja, de um conflito que não pode ser solucionado em função de quaisquer critérios normativos, mas cuja resolução é, ela mesma, a origem de padrões normativos. Nesse sentido, pode-se dizer, com perdão da redundância, que a decisão do soberano é decisiva, pois, como observa Schmitt, comentando Hobbes, ela "cria o direito, ao decidir a luta em torno do direito" $(D, 21)$. O ponto de vista extremo da exceção tornaria patente a importância da soberania como esse lugar de decisão sobre a natureza da própria ordem pública.

Para Schmitt, essa natureza última da decisão soberana e, portanto, a sua capacidade de instituir as condições concretas da vigência do direito se evidenciariam na sua competência para a revogação da ordem vigente: se o soberano decide sobre a na-

17 Para a idéia de Grenzbegriff, cf. PT, 13. 
tureza da ordem é porque ele está em condições de decidir sobre o estado de exceção. O soberano se apresenta como aquele que seria capaz de determinar o momento em que a norma, por não dar conta da situação concreta, precisaria ser suspensa. Porque não pode ser subsumida, circunscrita ou antecipada, a exceção precisa ser declarada, ou melhor, decidida. Mais precisamente: a exceção, já sabemos, não pode ser deduzida de nenhum princípio geral; não há, portanto, qualquer parâmetro a partir do qual seria possível reconhecer antecipadamente uma determinada situação como excepcional. Por isso, a decisão, para Schmitt, jamais tem um significado meramente declarativo, ela, pelo contrário, constitui o estado de exceção. Não se trata, portanto do simples reconhecimento de um certo estado de coisas. É o soberano quem decide quando as normas não mais se aplicam, suspendendo a sua validade. Ele decide sobre (über) o estado de exceção. A sua ação tornaria evidente que a norma não é universalmente válida e que não contém em si mesma o seu próprio fundamento. A contraface, portanto, da decisão sobre o estado de exceção é a decisão sobre a normalidade. $\mathrm{O}$ mesmo soberano que estabelece o estado de exceção, definindo uma situação como anormal, estaria em condições de determinar em que consiste a ordem pública, quando ela foi restabelecida, restaurada.

Ao transformar o ato de vontade envolvido numa decisão soberana no fator de instauração de uma ordem normativa, Schmitt tem como um de seus alvos a ideia liberal da "sociedade que encontra a norma em si mesma". No pensamento liberal, o fundamento da ordem social seria imanente a ela própria e o "dominação da norma" se apresentaria como o resultado de automatismos gerados no intercâmbio social entre os indivíduos. A admissão do "caso anormal" implica, para Schmitt, a recusa da possibilidade de submeter o conjunto da vida política a uma racionalidade normativa. A crença liberal numa ordem autorregulada deveria ceder lugar ao reconhecimento de que as bases de uma ordem normativa não poderiam nascer espontaneamente da própria sociedade, pelo contrário, elas viriam de fora. À imagem de uma harmonia resultante da livre concorrência entre os 
indivíduos - ou seja, à imagem de uma ordem justa das coisas como uma realidade oriunda da esfera privada e que se projeta sobre a vida pública - Schmitt opõe a ideia da ordem como algo originariamente público, fruto de um ato de vontade exterior ao intercâmbio entre indivíduos privados. Enfim, ao ideal de uma sociedade governada pelo princípio da imanência, Schmitt opõe o fundamento transcendente de toda situação normal. Todavia, num mundo em que a transcendência dos valores sobre os quais se fundamentava a autoridade perdeu grande parte da sua evidência pública, esse princípio transcendente é necessariamente formal ${ }^{18}$. Nesse sentido, conceitos como o de decisão e exceção desempenham na reflexão de Schmitt um papel central: o de lhe permitir pensar a ordem jurídico-política como algo que necessariamente transcende o caráter imediato e contingente da existência política, mas que, ao mesmo tempo, extrai a sua força da capacidade de criar, a partir dessa contingência, uma concepção unitária. A ordem é sempre, para ele, o resultado de uma mediação entre a indeterminação concreta das relações políticas e a abstração transcendente da ideia de unidade ${ }^{19}$. Em contraste com a noção de uma normalidade de princípio implícita nos dualismos liberais - ou seja, em contraste com a convicção de que o direito, a moralidade, as leis da razão, as normas da técnica são válidas em todas as circunstâncias -, Schmitt recorre a uma outra polaridade. Uma polaridade que, segundo ele, "retira desses conceitos a capacidade de se contraporem ao 'poder' sob a forma de oposições

18 Como observa Schmitt no seu livro sobre Thomas Hobbes, a "pessoa soberano-representativa" que surge com o pacto social seria necessariamente superior à vontade somada de todos os indivíduos participantes do contrato. Ela possuiria uma natureza "transcendente (...), ainda que certamente apenas em um sentido jurídico, e não metafísico" ( $L S T H, 52)$.

19 Nessa perspectiva, subscrevo a tese do importante livro de Carlo Galli, Genealogia della política (Bolonha: Il Mulino, 1996), segundo a qual Carl Schmitt pensa o problema da política (moderna) a partir de uma perspectiva originária e concebe esta origem em função de seus dois lados, que se contradizem e, ao mesmo tempo, se pressupõem reciprocamente: exceção, conflito concreto, ausência de ordem, por um lado; excesso, ideia transcendente, coação à ordem, por outro.

Ano $13 \cdot$ n. $1 \cdot$ jan./jun. $2013-161$ 
sumárias" ${ }^{20}$. Trata-se, enfim, da "oposição fundamental"21 entre normalidade e exceção. Essa antítese traz para frente de cena o “quis judicabit?" de uma decisão pessoal, que se apresenta não só como o fundamento de validade de uma ordem normativa, mas também como instância de mediação entre essa última e a realidade. Dessa forma, o decisionismo de Schmitt representa uma tentativa de pensar uma conformação da existência política que, sem abolir a tensão entre norma e realidade, evite a sua exclusão recíproca e seja, ao mesmo tempo, "o fundamento concreto para uma forma substancial" $(R K, 50)^{22}$.

Com isso, o significado lógico e - por que não dizer? - metafísico do conceito de exceção na obra de Carl Schmitt se torna evidente. Por um lado, ele se apresenta como "critério para o conhecimento teórico e para a elaboração conceptual"23. À exceção - caso-limite, mas também princípio sistemático - estão logicamente associadas outras categorias, como, por exemplo, decisão, ditadura, soberania. Por outro lado, a exceção é, no seu pensamento, a contrapartida da noção de uma ordem universal, imamente e autoinstituída, que acredita conter em si a totalidade das situações particulares. Ela é um pressuposto central da imagem que Schmitt nos apresenta da realidade concreta da vida social e política como algo precário e contingente. Mais do que uma tentativa de descrição realista do mundo da política, a ideia de exceção é uma espécie premissa metafísica, a partir da qual a condição política do homem - e, mais especificamente, a condição política do homem moderno - é pensada em termos de uma

\footnotetext{
20 "Zu Friedrich Meineckes Idee der Staatsräson" (1926) in PuB, 57.

21 "Zu Friedrich Meineckes Idee der Staatsräson" (1926) in PuB, 53.

22 Uma análise mais detida desse problema exigiria uma discussão do livro Römischer Katholizismus und politische Form (Catolicismo romano e forma política) e dos conceitos de representação e forma política, coisa que não será possível fazer nos limites desse artigo. Para uma abordagem dessas questões, remeto ao capítulo $\mathrm{V}$ do meu livro O risco do político. Critica ao liberalismo e teoria política no pensamento de Carl Schmitt.

23 Orfanel, G. G. Excepción y normalidade en el pensamiento de Carl Schmitt. Madri: Centro de Estudios Constitucionales, 1986, p. 37.
} 
indeterminação essencial.

Como vimos, o ponto de vista da exceção não apenas revelaria o fundamento decisionista de toda situação normal, como também poria a nu a vanidade da pretensão liberal de substituir o "governo dos homens" pelo "governo da lei", de neutralizar as relações de força, de poder, de dominação e de - quem sabe? - banir o próprio conflito na convivência humana. A crença na possibilidade de circunscrever normativamente a exceção seria, portanto, inseparável tendência à despolitização da vida social característica do liberalismo. Eliminar a exceção seria o mesmo que, em última análise, eliminar a política da face da Terra, pois significaria conter a totalidade das relações humanas em um conjunto de regras universalmente válidas. Em uma circunstância como essa, a vida social poderia ser inteiramente previsível, já que "tudo 'and[aria] por si só', as coisas se 'administr[ariam] por si mesmas' e um governo dos homens pelos homens se torn[aria] supérfluo" $(B P, 58)$.

A imagem liberal de uma ordem autorregulada - em que as relações de força e de dominação poderiam ser neutralizadas e os conflitos entre os homens se resolveriam através da livre concorrência - está associada, segundo Schmitt, a uma "profissão de fé antropológica" (BP, 58). Com efeito, observa ele, essa imagem só é compatível com uma concepção otimista da natureza humana. É preciso supor que o homem seja um ser essencialmente "bom" para que o caráter pacífico e espontâneo da ordem liberal faça algum sentido. Essa "bondade natural", nos diz Schmitt, pode se apresentar das mais diversas formas - "racionalidade, perfectibilidade, docilidade, educabilidade, simpática pacificidade, etc." $(B P, 59)$-, o que permanece, porém, é o fato de que a "normalidade de princípio" da perspectiva liberal não se sustenta sem a hipótese de uma disposição inofensiva do homem. Em outras palavras, só seria possível falar de uma ordem autorregulada quando se acredita que a conduta humana não introduz perturbações decisivas no curso da vida social, ou seja, quando se acredita que a ação humana não é fonte de desordem e inimizade e que, portanto, não necessita ser governada. 
Para Schmitt, pelo contrário, a admissão da possibilidade à situação-limite da exceção tornaria problemático uma perspectiva baseada no otimismo antropológico. A seu ver, todo pensamento verdadeiramente político precisa levar em conta a indeterminação e o potencial de desordem inerentes à vida política. O reconhecimento da possibilidade da inimizade e da exceção implicaria uma imagem do homem "como um ser de forma alguma não problemático, mas sim dinâmico e "perigoso"” $\left.{ }_{(B P,} 61\right)$. Essa referência ao fundamento antropológico das teorias políticas tem, no entanto, um estatuto ambíguo.

Por um lado, mais do que a premissa a partir da qual Schmitt deriva a sua imagem da política, a sua insistência na periculosidade do homem pode ser vista como uma hipótese com a qual toda verdadeira teoria política tem que contar. Como observa Michele Nicoletti, o ponto de vista de Schmitt é existencial e não substancialístico: o reconhecimento da "possibilidade do perigo como situação extrema, como possibilidade de fazer o mal" "24 coloca a exigência de uma antropologia pessimista e torna toda perspectiva otimista a respeito da natureza humana incompatível com uma autêntica teoria política. No pensamento de Schmitt,

24 Nicoletti, Michele - Trascendenza e potere, p. 280. Em outra oportunidade o mesmo comentador observa: "a maldade do homem - ou, melhor a sua periculosidade (que não significa que o homem deve necessariamente e exclusivamente realizar ações más, mas apenas que pode realizá-las) - não é dogmaticamente afirmada, mas mais tomada como hipótese e pressuposta em um esforço de previsão de todos os comportamentos humanos que o político deve necessariamente fazer". Nesse sentido, prossegue Nicoletti, "a escolha antropológica é uma profissão de fé, muito mais do que um conhecimento certo" (pp. 280-281, nota 43; ver também pp. 123-124). Jean-François Kervégan, por sua vez, afirma que seria difícil definir se o pessimismo antropológico de Schmitt se justifica por uma questão de coerência com sua imagem da existência política ou se, pelo contrário, funda essa imagem. (cf. op. cit. , p. 74). Kervégan parece concluir pela primeira opção, ao afirmar que a oposição entre uma antropologia pessimista e uma otimista seria um "meio cômodo de distinguir entre uma compreensão política da política e sua negação liberal" (ibid., p. 117). Já para um autor como Heinrich Meier, o núcleo da análise de Carl Schmitt do político estaria na própria idéia de pecado original, vide Meier, H. - Carl Schmitt, Leo Strauss et la notion de politique, Paris, Julliard, 1988 e The lesson of Carl Schmitt, Chicago, Chicago University Press, 1998. 
essa imagem do homem como um "ser problemático" é indissociável da exceção como categoria a partir da qual a realidade política é pensada: afirmar a periculosidade do homem é admitir a impossibilidade de superar os antagonismos entre grupos humanos e assumir a indeterminação como uma condição da existência política. Dessa forma, não é tanto uma antropologia pessimista que Schmitt opõe ao otimismo de fundo do pensamento liberal, mas a antítese entre normalidade e exceção, situação normal e situação fora da norma. Como ele mesmo observa,

"na literatura sobre a teoria do Estado, a idéia de que o
homem é bom por natureza ou mau por natureza é, de
uma forma geral, apenas uma paráfrase [Umschreibung] ou
uma aplicação particular dessa oposição fundamental" 25 .

Por outro lado, a discussão sobre os pressupostos antropológicos das teorias políticas têm uma marca claramente polêmica. Ela está voltada contra as despolitizações e neutralizações do liberalismo e pode ser encarada como uma tentativa de formular uma "ontologia" contraposta à ontologia liberal. Nessa perspectiva, a sua insistência nos pressupostos antropológicos do pensamento político e na natureza inelutável do político pode ser vista como uma tentativa de afirmar, polemicamente, no interior da própria contingência do mundo moderno algo de imperativo e, por assim dizer, inerente à natureza das coisas. Nesse quadro, uma vez mais, a sua polêmica contra o liberalismo tem um lugar central. A imagem de uma indeterminação essencial da vida política em Schmitt tem como alvo, entre outras coisas, a crença liberal na possibilidade de construir uma ordem essencialmente pacífica e autorregulada. Em certa medida, a "profissão de fé antropológica" e a ideia da inevitabilidade das situações de exceção podem ser vistos como o desdobramento de uma observação que Schmitt faz em Teologia política. Segundo ele, a pergunta sobre

25 "Zu Friedrich Meineckes Idee der Staatsräson" (1926) in PuB, 53.

Ano $13 \cdot$ n. $1 \cdot$ jan./jun. $2013-165$ 
a possibilidade de banir do mundo o caso de exceção "não é uma questão jurídica". Isso porque, prossegue Schmitt,

"a confiança e a esperança de que ele se deixe efetivamente eliminar dependem de convicções filosóficas, em particular, de convicções metafísicas ou filosófico-históricas" $(P T, 14)$.

Para Schmitt, o pensamento político jamais é uma simples asserção de fatos, ele envolve, necessariamente, postulados indemonstráveis, algum tipo de "profissão de fé", a partir dos quais a realidade vem a ser concebida. Assim, ao colocar o problema do fundamento antropológico das teorias políticas, Schmitt procura pôr em evidência os pressupostos metafísicos sobre as quais se baseia a ontologia liberal e a sua crença na superação da política. Por outro lado, o conceito de exceção, assim como o pessimismo antropológico que lhe é inerente teriam, como ele mesmo observa, um significado "metafísico-lógico"26 e podem ser vistos como premissas de outra "ontologia", de feição marcadamente polêmica. Trata-se, entretanto, de uma "ontologia", para dizer o mínimo, problemática. Longe de apontar, para algum tipo de fundamentação da ordem, ela lhe subtrai os fundamentos e nos oferece uma imagem essencialmente trágica da condição política. Enquanto a ordem liberal partiria da imagem de que os princípios da vida pública resultam de uma coincidência da sociedade consigo mesma, Schmitt reafirma a necessidade do governo do homem pelo homem e da decisão como fator de estruturação da ordem. Em lugar da emancipação face ao Estado e à política, em lugar da dinâmica autorregulada da vida em sociedade, Schmitt insiste que "a política continua a ser o destino" (BP, 77). Dessa forma, sua reflexão política pode ser vista como uma tentativa de fazer uma “ontologia” política do social.

26 “Zu Friedrich Meineckes Idee der Staatsräson" (1926) in PuB, 53.

166 - Universidade Católica de Pernambuco 


\section{Bibliografia}

BEAUD, Olivier. "Carl Schmitt ou le juriste engagé" In : SCHMITT, Carl. Théorie de la Constitution, Paris, PUF, 1993

DUSO, Giuseppe. La rappresentanza: un problema di filosofia política. Milão: Franco Angeli, 1988

FREUND, Julien - "Schmitt's political thought" in Telos, $\mathrm{n}^{\circ}$ 102, 1995 FERREIRA, Bernardo. O risco do político. Critica ao liberalismo e teoria política no pensamento de Carl Schmitt. Belo Horizonte: UFMG, Rio de Janeiro: IUPERJ, 2004

GALLI, Carlo. Genealogia della Politica. Bolonha: Il Mulino, 1996 HOFMANN, Hasso. Legittimità contro Legalità. Nápoles: ESI, 1999 KERVÉGAN, Jean-François - Hegel, Carl Schmitt. Le politique entre spéculation et positivité, Paris, Puf, 1993

. "La critique schmittienne du normativisme kelsénien" In: HERRERA, Carlos-Miguel (org.). Le Droit, le Politique. Autour de Max Weber, Hans Kelsen, Carl Schmitt, Paris, L'Harmattan, 1995

LESSA, Renato. A política como ela é ... Carl Schmitt e o realismo político como agonia e aposta. In: Agonia, aposta e ceticismo. Belo Horizonte: Editora UFMG, 2003

LÖWITH, Karl. "Der okkasionelle Dezisionismus von Carl Schmitt" (1935) In: Gesammelte Abhandlungen. Stuttgart: Kohlhammer, 1960 MEIER, Heinrich. Carl Schmitt, Leo Strauss et la notion de politique. Paris: Julliard, 1988

1998

. The lesson of Carl Schmitt, Chicago, Chicago University Press,

NICOLETTI, Michelle. Trascendenza e Potere. La teologia politica di Carl Schmitt Brescia: Morcelliana, 1990

ORFANEL, G. G. Excepción y normalidade en el pensamiento de Carl Schmitt. Madri: Centro de Estudios Constitucionales, 1986

PASQUINO, Pasquale. "Carl Schmitt - Teoria da constituição" in CHATELET, F.; DUHAMEL, O.; PISIER, E. Dicionário de obras políticas. Rio de Janeiro Civilização Brasileira, 1993

SCHMITT, Carl. Der Begriff des Politischen. 6.ed. Berlim: Duncker \& Humblot, 1996. (texto de 1932, reimpresso a partir da edição de 1963, que foi acrescida de um novo prefácio e de notas adicionais).

. Die Diktatur. Von den Anfängen des modernen Souveränitätsgedankens bis zum proletarischen Klassenkampf. 6.ed. Berlim: Duncker \& Humblot, 1994. (reimpressão da $2^{\mathrm{a}}$ ed. de 1928).

. Die geistesgeschichtliche Lage des heutigen Parlamentarismus.

Ano $13 \cdot$ n. $1 \cdot$ jan./jun. $2013-167$ 
8.ed. Berlim: Duncker \& Humblot, 1996. (reimpressão da $2^{\text {a }}$ ed. de 1926).

. Der Hüter der Verfassung. 4.ed. Berlim: Duncker \& Humblot, 1996. (1 ${ }^{\mathrm{a}}$ ed. 1931).

. Legalität und Legitimität. 5.ed. Berlim: Duncker \& Humblot, 1993. (1 ${ }^{\mathrm{a}}$ ed. 1932).

. Der Leviathan in der Staatslehre des Thomas Hobbes. Stuttgart: Klett-Cotta, 1982 ( $1^{\text {a }}$ ed. 1938).

. Politische Theologie. 7.ed. Berlim: Duncker \& Humblot, 1996. (reimpressão da $2^{\mathrm{a}}$ ed. de 1934).

. Positionen und Begriffe. 2.ed. Berlim: Duncker \& Humblot, 1988. (1 $1^{\text {a }}$ ed. 1940).

. Römischer Katholizismus und politische Form. Stuttgart: KlettCotta, 1985. (reimpressão da $2^{\mathrm{a}}$ ed. de 1925)

. Über die drei Arten des rechtswissenschaftlichen Denkens. 3.ed. Berlim: Duncker \& Humblot, 1993. ( $1^{\text {a }}$ ed. 1934).

. Verfassungslehre. 7.ed. Berlim: Duncker \& Humblot, 1989. (1 ${ }^{\mathrm{a}}$ ed. 1928).

SCHWAB, George. The Challenge of exception. Nova York: Greenwood, 1989, $2^{\mathrm{a}}$ ed.

PORTINARO, Pier Paolo. La Crisi dello Jus Publicum Europaeum. Milão: Comunità, 1982

STRAUSS, Leo. "Anmerkungen zu Carl Schmitt, Der Begriff des Politischen” (1932). In: Hobbes’ politische Wissenschaft. Neuwied: Luchterhand, 1965 